\title{
Cycling for health: forty years ago
}

\author{
O L Wade
}

Although it is now 40 years ago I remember 19 December 1953 very well. I had gone to Birmingham University in 1951 to join Ken Donald, John Bishop, and Gordon Cumming in the department of medicine under Professor Melville Arnott. Donald had worked in New York with André Cournand, who was a pioneer in the use of cardiac catheterisation to investigate congenital lesions of the heart and the haemodynamics of patients with heart disease.

It was the early days of open heart surgery and surgeons could open the left atrium, insert a finger through a stenosed mitral valve, and split it, thus improving the flow of blood and giving the patient much relief. But it was a disaster if at operation it was found that the valve was not stenosed, for there was at that time no way in which an incompetent mitral valve could be repaired or replaced, and the patient would have had a thoracotomy and the heart opened for no useful purpose.

We hoped that by passing a catheter from an arm vein into the right atrium and through the right ventricle to the pulmonary artery, and by recording the intracardiac pressures, including the pressure in the left atrium, by impacting the catheter in one of the pulmonary vessels, we would be able to diagnose mitral stenosis with greater precision. While doing this we could estimate the cardiac output if we took a sample of the venous blood from the pulmonary artery and of the arterial blood from a brachial artery and estimated the patient's oxygen uptake per minute by collecting and analysing the expired air.

\section{Measurements in patients at rest and at exercise}

Thus it was that over the next nine months we measured intracardiac pressures and cardiac output at rest in patients with rheumatic heart disease. It was demanding work because each blood and gas sample had to be analysed in duplicate by time consuming manual methods. The four of us were often working in the lab till 10 or $11 \mathrm{pm}$. It was soon clear that more useful information might be obtained if we could measure the intracardiac pressures and the cardiac output during exercise, but we realised that such an investigation would be difficult and arduous because of the large number of blood and gas samples we would have to analyse.

It was a fortunate coincidence-and such coincidences are most necessary to most research workers -that M W A Gatman, a New Zealander working in Sheffield, had recently developed a much faster method $^{1}$ of measuring the oxygen content of small samples of blood by spectrophotometry. This new method made it possible for us to make observations taking frequent samples of mixed venous blood in patients before, during, and after exercise. The exercise was pedalling a bicycle ergometer that we fixed to the end of the $x$ ray table on which the patients lay when we screened them to pass the catheter into the heart.

What we found was dramatic, rather unexpected, and very exciting. ${ }^{2}$ In patients with heart disease the cardiac output, which may be very low at rest, may hardly rise at all during quite heavy exercise. The increased oxygen needed by the exercising muscles is obtained by extracting more oxygen from the circulating blood-so the venous blood returning by

the great veins of the thorax to the right side of the heart is greatly desaturated. The blood leaves the lungs almost fully saturated (96-98\%) but returns perhaps only $20-30 \%$ saturated, looking rather like black ink.

\section{Measurements made in ourselves}

At that time there was limited knowledge of the cardiac output in normal subjects during exercise. The few measurements that had been made in human beings had been made in the days before cardiac catheterisation, using methods of breathing nitrous oxide or acetylene or by dye dilution techniques. Measurements with these methods during exercise were very difficult, and there had always been much doubt about their reliability. By December 1953 we had decided that it was essential to make measurements in normal subjects during exercise to be able to interpret correctly the results we had found in our patients.

This was not something to be entered upon lightly. The idea of putting a catheter into the human heart was still considered with trepidation by most physicians at that time. It was thought justifiable for diagnostic purposes in a patient with heart disease. But the idea of putting a catheter into the heart of a normal person even at rest was highly suspect, and to do it during exercise was, I think, totally unacceptable to everyone who had not seen, as we had seen, how apparently harmless it had been to our patients. We decided we would go ahead but that in the first instance we would do the studies in ourselves. ${ }^{3}$

The first study was done on 16 December 1953. Ken Donald, the leader of our team, was the first to be studied. I did the catheterisation and all went well and smoothly. It was perhaps just as well that I did not know till many years later that Ken-fearing that if some catastrophe occurred, such as ventricular fibrillation (defibrillators had not been thought of in those days) I might be crucified by a coroner-had written a letter which he had put in his desk to be opened if he died, explaining that he took full responsibility for the investigation and for any ill effects that might accrue to him.

I was confident of the safety of the procedure and had no qualms about being the second subject three days later. Ken catheterised me. Just as my patients had told me, I was aware only of Ken fiddling about, twisting and pushing the catheter, at my left elbow and I could not feel the catheter in my heart at all. Indeed it was interesting and rather comforting to hear my colleagues' comments as they peered at the $x$ ray screen and watched as the tip of the catheter was being edged along through the heart chambers into the pulmonary artery. The arterial needle inserted into the right brachial artery under local anaesthetic was of course painless-I had often previously had meals with an arterial needle in my arm.

When the catheter was in place John Bishop put a clip on my nose and a mouthpiece into my mouth and samples of venous and arterial blood were taken while my expired breath was collected, and put aside for analysis while I lay still on the $x$ ray table.

Then my colleagues moved the bicycle pedals up to the bottom of the table. I put my feet on them and off I went pedalling. It was quite hard work, and keeping the speed indicator at its right position occupied my 


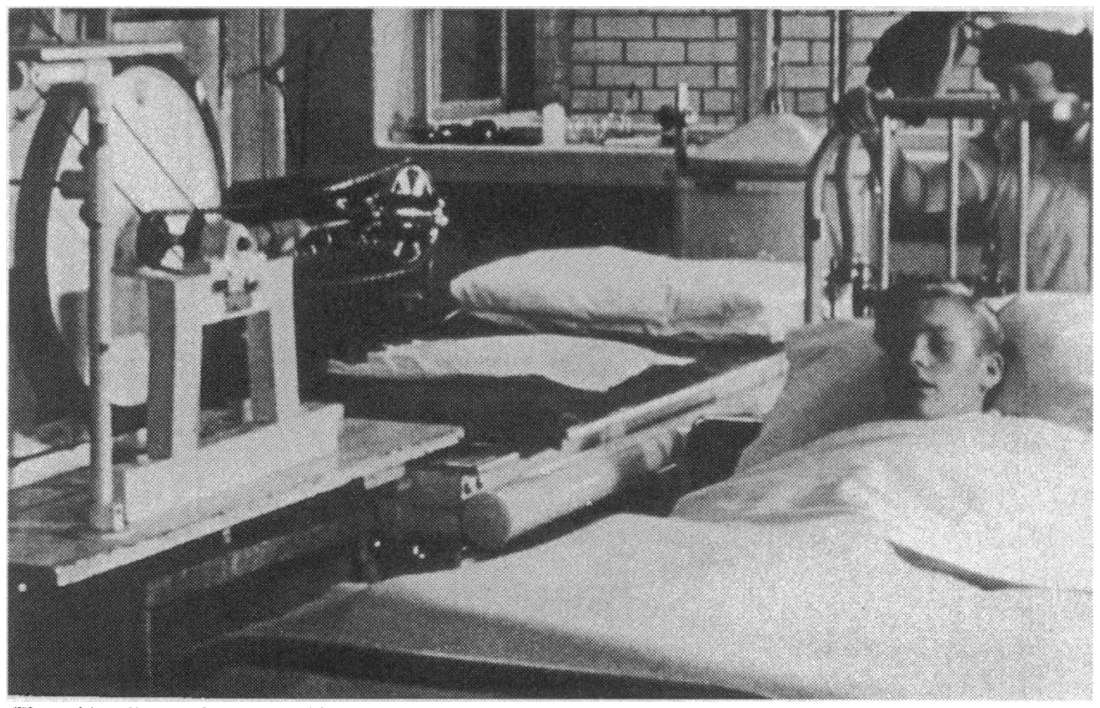

The subject lies on the $x$ ray table so that a catheter can be guided visually through the right atrium and right ventricle into the pulmonary artery. He then exercises on the bicycle ergometer attached to the bottom of the table. Note the big Tissot spirometer behind the table, used to collect expired air from subjects as they exercised mind totally for the next five minutes. Then I could relax and rest while my colleagues continued taking my blood and gas samples for another five minutes.

When the catheterisation was finished I got up, dressed, and helped with the spectrophotometric analyses of the 30 blood samples that had been taken from me. During the last three minutes of the bicycle exercise that afternoon my mean oxygen consumption was $1044 \mathrm{ml} / \mathrm{min}$ and my mean cardiac output was $13 \cdot 29 \mathrm{l} / \mathrm{min}$.

I did not tell my wife about it till much later. I thought she might be rather cross that I had not discussed it with her in advance, and I did not want to start off the Christmas holiday with any arguments.

We studied 16 normal subjects, 12 men and four women. The first four were the four of us who had planned the investigation, Ken, myself, John, and Gordon. All the others were colleagues who were either doctors or nurses. We were especially proud of the fact that when we decided to include women in the study, our ward sister, Sister Shelagh Churton, immediately told us that she felt she had the right to be the first woman subject. Staff Nurse Mary Woods, who had worked with the catheterisation team for three years and knew better than anyone else the standard of our work, insisted on being the second female subject. Such enthusiasm in relation to research is something very precious and very dear to the heart of those of us who have on occasion encountered very different sentiments.

\section{Conclusion}

This work added considerably to the understanding of the cardiac and vascular changes that occur during exercise. It led us on to show that not only does the cardiac output increase during exercise but that there are changes in the distribution of the blood that the heart pumps so that the non-exercising parts of the body, including the liver and the kidneys, get less blood so that more can go to the exercising muscles. This is important to all who take heavy exercise. Think about it as you watch the next Olympic games. And think of it too as you watch your patients with cardiac insufficiency, for if this redistribution did not take place they would be far more disabled than they are. We were amazed to find that exercising muscles can extract almost all the oxygen from the blood that goes to them. On occasion we sampled venous blood which was almost zero saturated from the femoral vein of patients cycling.

I look back on the time of that research as one of the most satisfying and exciting periods in my professional life. Every now and then when I roll up my sleeves I glance down at my left elbow. I can still see, with difficulty now for it has faded, the small scar where the catheter was inserted into my median basilic vein. Time rolls back and it is 19 December 1953, forty years ago.

I thank Trevor Hayward for a splendid job of making prints from a 40 year old film.

1 Wade OL, Bishop JM, Cumming G, Donald KW. A method for the rapid estimation of the percentage oxygen saturation and oxygen content of blood. BMY 1953;ii:902-5.

2 Donald KW, Bishop JM, Cumming G, Wade OL. A study of minute-to-minute changes of the arterio-venous orygen content difference, oxygen uptake and cardiac output and rate of achievement of a steady state during exercise in carciamatic heart disease. $f$ Clin Invest 1954;33:1146.

3 Donald KW, Bishop JM, Cumming G, Wade OL. The effect of exercise on the cardiac output and circulatory dynamics of normal subjects. Clin Sci 1955;14:37-73.
Alan Woodruff (see p 1623) engraved "Emergent Africa: the University of fuba, southerm Sudan" in 1981 as the first students started their clinical studies. The clock tower was never completed and civil war meant the medical school had to move to Khartoum
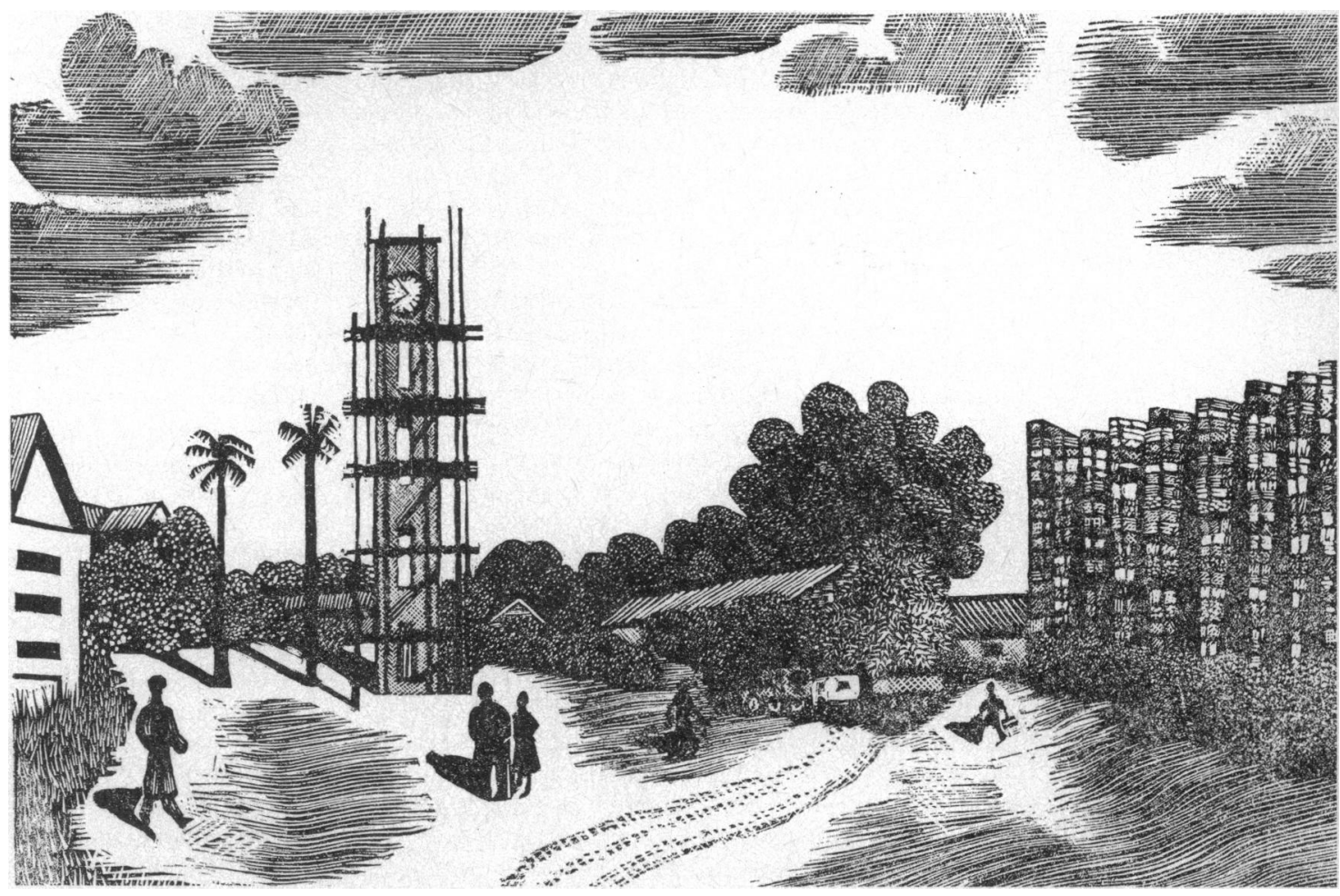